\title{
Evaluation of transverse changes in the dental arches according to growth pattern: a longitudinal study
}

\author{
Jucienne Salgado Ribeiro*, Aldrieli Regina Ambrosio**, Ary dos Santos-Pinto***, \\ Isabella Almeida Shimizu ${ }^{\star \star \star \star}$, Roberto Hideo Shimizu $u^{\star \star \star \star \star}$
}

\begin{abstract}
Objective: To evaluate changes in intercanine (LICW and UICW) and intermolar (LIMW and UIMW) widths on the dental arches of subjects with normal occlusion and Angle Class I malocclusion during the transition to permanent dentition, and evaluate whether or not facial pattern influences on the normal development of the dentition and occlusion. Methods: Nineteen Caucasian Brazilian children were selected, with ages ranging from 6 to 8.6 years at $\mathrm{Tl}$ and from 10.10 to 14.2 years at T2. Their second records consisted of study dental casts and a lateral cephalometric radiograph. To obtain intermolar and intercanine widths a three-dimensional scanner unit (digitizer MicroScribe 3DX) was used connected to a microcomputer. To analyze changes at T1 and T2 Student's paired t-test was applied, whereas Spearman's correlation analysis was used to assess the relationship between measurements obtained at $\mathrm{T} 1$ and $\mathrm{T} 2$ and the facial pattern, both at $95 \%$ level of confidence. Results: The mean values found on each assessment time (T1 and T2) were statistically different ( $\mathrm{p}=0.000$ for LICW, $\mathrm{p}=0.001$ for UICW, $\mathrm{p}=0.000$ for UIMW, and $\mathrm{p}=0.046$ for LIMW), regardless of the facial pattern. The anterior dimensions, UICW and LICW, increased by $3.21 \mathrm{~mm}$ and $1.52 \mathrm{~mm}$, respectively. And the posterior dimensions, UIMW and LIMW, increased by $2.16 \mathrm{~mm}$ and $0.50 \mathrm{~mm}$, respectively. Only UIMW showed a significant correlation with the facial pattern $(\mathrm{p}<0.01)$. Conclusion: There was an increase in dental arch width during the transition period from primary or mixed dentition to permanent dentition irrespective of facial pattern. Only the changes observed in the maxillary intermolar width were associated with the facial pattern.
\end{abstract}

Keywords: Transverse changes. Intercanine width. Intermolar width. Facial pattern.

How to cite this article: Ribeiro JS, Ambrosio AR, Santos-Pinto A, Shimizu IA, Shimizu RH. Evaluation of transverse changes in the dental arches according to growth pattern: a longitudinal study. Dental Press J Orthod. 2012 Jan-

Feb;17(1):66-73.
" The authors report no commercial, proprietary, or financial interest in the products or companies described in this article.

* MSc in Orthodontics, Pontifical Catholic University of Paraná (PUCPR) Scholarship granted by the Brazilian Federal Agency for Support and Evaluation of Graduate Education (CAPES).

** MSc in Orthodontics, PUCPR. PhD student in Orthodontics FOAr-UNESP. Professor, Orthodontics Graduate Program, SOEPAR.

*** Senior Assistant Professor, Children's Clinic Department, School of Dentistry of Araraquara - São Paulo State University (FOAr-UNESP).

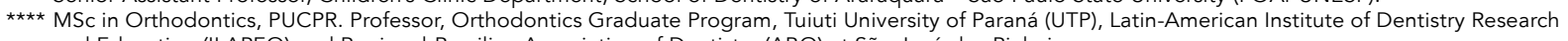
and Education (ILAPEO) and Regional-Brazilian Association of Dentistry (ABO) at São José dos Pinhais.

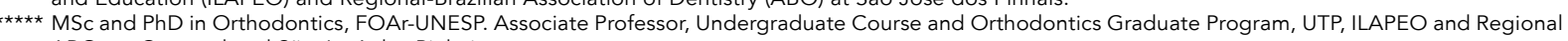
$\mathrm{ABOs}$ at Cascavel and São José dos Pinhais. 


\section{INTRODUCTION}

Dimensional changes in dental arches are compensatory mechanisms that occur as a result of growth and are required in order to maintain a balance between the functional and structural needs of the face and dentition., 48 The dimensions of the dental arches change systematically during growth and development period, even if no treatment is administered. ${ }^{8}$

The dimensions and morphology of the dental arches have considerable impact on orthodontic diagnosis and treatment planning, affecting space availability, dental esthetics, dentition stability and the prospects for a favorable development. ${ }^{11,15}$

Changes in the dimensions of the dental arches have been studied since 1890, when Zsigmondy, ${ }^{29}$ using three sets of dental casts from an individual sample of children between the ages of 6 and 17 years, measured for the first time the length of the dental arches. Clinch ${ }^{10}$ and Sillman $^{23}$ however, were the first to present the development process of the dentition since birth.

Many authors have investigated the transverse changes that occur during the development of dentition and occlusion, which consist mainly of the intercanine and the intermolar widths. ${ }^{2,3,7,14,22,25}$

By studying the development of dental arches in children aged 5 to 8 or 9 years a rapid increase in intercanine width was observed $(4 \mathrm{~mm}$ in the maxilla and $3 \mathrm{~mm}$ in the mandible). The cusp tips of canines were used as reference points for the measurements. ${ }^{2}$

Another assessment that has been performed in longitudinal studies is related to the occlusion type, that can be established early in life. In other words, based on the characteristics of the occlusion of deciduous teeth it is possible to predict the occlusion of permanent teeth. ${ }^{1,7,22,24} \mathrm{By}$ observing the maxillary and mandibular intercanine width from birth to adulthood in a longitudinal study, the behavior of these dimension in the different stages of dentition were reported.
It was found that from birth to 13 years of age a continuous increase in the maxillary and mandibular intercanine width occurred, whereas no significant changes were detected after that age. ${ }^{25}$

A study that sought to correlate the facial pattern with the dental arches' width found some relatively weak correlations in non-growing individuals. ${ }^{12}$ Studies that subdivided the sample by gender found that, in women, the correlation was only identified in the region of maxillary second premolars, with no correlation in the mandible. In men, correlations were found in maxillary and mandibular intercanine and inter-first premolar width and maxillary inter-second premolars and first molars. ${ }^{12}$

In general, studies available in the literature describe the changes in the dental arches by attempting to correlate them with the type of occlusion, individual growth pattern, ${ }^{12,20}$ gender, ${ }^{12}$ existence of crowding or spaces, ${ }^{12}$ among others.

Correlation studies have only addressed growth pattern on specific occasions, both with growing and non-growing subjects. These studies are essential for planning preventive actions or treatment, for which successful outcomes depend, in part, on changes in the teeth and facial growth ${ }^{18}$. Therefore, identifying any potential relationship between growth pattern and dimensional changes in the dental arches caused by normal growth could alter prospects, orthodontic planning and treatment.

\section{OBJECTIVE}

The aim of this longitudinal study was to evaluate transverse changes in the dental arches of individuals with normal occlusion or Angle Class I malocclusion during mixed dentition and to assess whether these changes correlate with the growth pattern of the individuals.

\section{MATERIAL AND METHODS}

\section{Sample selection}

This research project was approved by the Ethics in Research Committee of the Center of 
Biological and Health Sciences (CEP-CCBS) at the Catholic University of Paraná, identified by file number 111 .

To obtain the initial complementary exams of the subjects, the 1998 records archived at the Graduate Dentistry Program department, Orthodontics concentration area, were utilized. Selection of the initial sample was intentional and convenient, comprising 19 Caucasian Brazilian children ( 7 males and 12 females) aged between 6 and 8.5 years, displaying normal occlusion or Angle Class I malocclusion.

From these individuals, dental casts and lateral cephalometric radiographs were obtained in the year 2003, when they were aged between 10 years and 10 months and 14 years and 2 months old.

\section{Obtaining and evaluating lateral cephalograms}

Lateral cephalograms were obtained in the Radiology Clinic of Dentistry, Pontifical Catholic University of Paraná, according to the technique standardized by Broadbent. ${ }^{5}$

All cephalometric tracings were performed twice by a single operator, three months apart. The angular measurements were taken with the aid of a protractor with 0.5 degree accuracy, with values being rounded up to the highest degree. The linear measures were determined with a digital caliper with $1 / 10 \mathrm{~mm}$ accuracy.

The measures considered for this purpose were FMA, SN.GoGn and the PFH/AFH Index. Individuals with FMA values lower than $21^{\circ}$, SN.GoGn lower than $30^{\circ}$ and Index greater than 0.75 were classified as brachyfacial, whereas individuals with FMA between $21^{\circ}$ and $29^{\circ}$ (inclusive), SN.GoGn between $30^{\circ}$ and $34^{\circ}$ (inclusive) and index between 0.65 and 0.75 (inclusive) were classified as mesofacial and finally those with FMA angular values over $29^{\circ}$, SN.GoGn higher than $34^{\circ}$ and Index values lower than 0.65 were classified as dolichofacial. When all measures were considered, only those individuals who remained in the same facial pattern group from beginning to end were included in the sample. No subject was excluded due to changes in facial pattern.

\section{Study dental casts fabrication}

Study dental casts were made from alginate impressions obtained with sterile trays and wax bite registration of dental occlusion in habitual maximum intercuspation. These casts were used to obtain measurements of the upper and lower dental arches.

\section{Measurement of digitized dimensions}

For landmark demarcation, pre-determined points were used on the upper and lower study dental casts according to the method described by Moyers. ${ }^{19}$

After proper calibration of the device and operator the data gathering process was initiated using a three-dimensional scanner unit, Digitizer MicroScribe 3DX (Fig 1) (Immersion, California, USA) connected to a computer as a measuring instrument.

The points shown in Figures 2 and 3 were scanned into an Excel spreadsheet (Microsoft, Redmond, USA), where the study measurements were calculated.

All dental casts were scanned at two different times to control error. Therefore, the values used in the study were the arithmetic means between these two assessments.

» Intercanine width - The distance between the cusps of the upper canines were measured to obtain the upper intercanine width (UICW) and similarly, the distance between the cusps of the lower canines were measured to obtain the lower intercanine width (LICW) (Figs 2 and 3).

"Intermolar width - The distance between the midpoint of the mesiopalatal, distopalatal, mesiobuccal and distobuccal cusps of the maxillary first molars were calculated to determine the upper intermolar width (UIMW). In the case of 


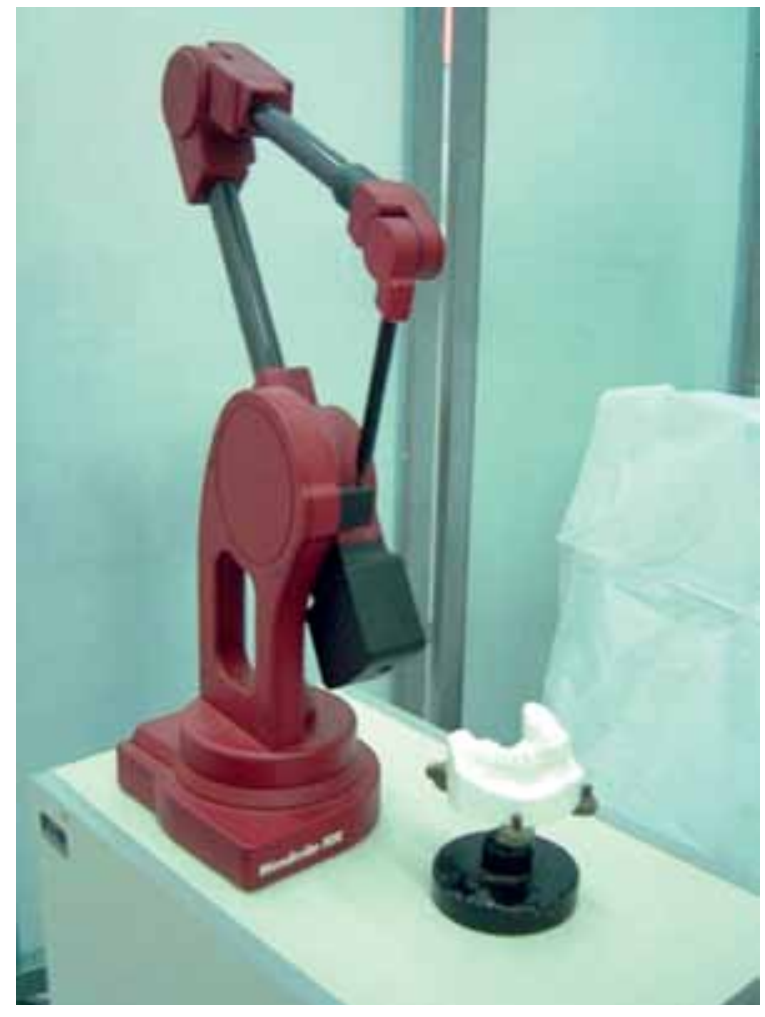

FIGURE 1 - Digitizer MicroScribe 3DX.

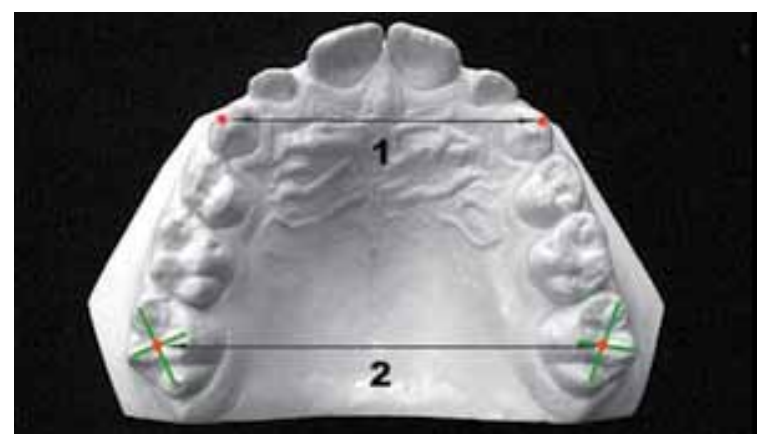

FIGURE 2 - Upper intercanine width (1), Upper intermolar width (2).

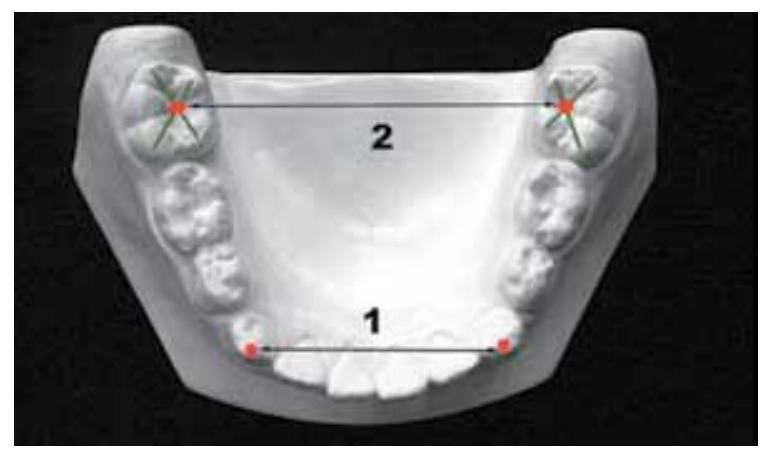

FIGURE 3 - Lower intercanine width (1), Lower intermolar width (2). the lower intermolar width (LIMW) the distances between the midpoint of the mesiolingual, distolingual, mesiobuccal and distobuccal cusps (Figs 2 and 3) were measured.

When a tooth was missing at the time of final evaluation due to the physiological replacement of a deciduous tooth by a permanent tooth, this measure could not be determined and therefore the data were excluded from the sample. Due to this fact, in those cases the sample consisted of only 18 individuals instead of 19 .

\section{METHOD ERROR}

Reproducibility of all data was confirmed by Dahlberg's Formula. The paired t-test (Table 1) was applied to test for systematic error. The test confirms that the measurements obtained were not statistically different at a significance level of $5 \%$ for $n-1$ degrees of freedom, since the $t$ values were lower than 2.03 , confirming that the data are reliable.

\section{STATISTICAL ANALYSIS}

All dimensions presented a normal distribution when analyzed by the Kolmogorov-Smirnov test at 5\% alpha level. Therefore, a paired Student's t-test was applied to check for differences between $\mathrm{Tl}$ and $\mathrm{T} 2$ for all arch widths examined, initially disregarding the facial pattern.

TABLE 1 - Paired t-test to evaluate systematic error.

\begin{tabular}{ccccc} 
Variable & $\mathbf{n}$ & $\begin{array}{c}\text { Difference } \\
\text { between } \\
\text { means }\end{array}$ & $\mathbf{s}^{2}$ & $\mathbf{t}$ \\
\hline UICW & 36 & 0.1288 & 0.15177 & 1.9850 \\
LICW & 38 & 0.1289 & 0.20444 & 1.7580 \\
UIMW & 36 & -0.0563 & 0.11815 & 0.9842 \\
LIMW & 36 & -0.0719 & 0.12124 & 1.2396
\end{tabular}

Note: $t$ values according to $n-1$ degrees of freedom, lower than 2.0301 for $n=36$ and lower than 2.0262 for $n=38$, indicating that there is no difference at a significance level of $5 \%$. 
The descriptive analysis of the variables was performed according to facial pattern, regardless of the assessed moment. The Spearman correlation test with a confidence level of $95 \%$ was used to verify whether there was any correlation between the facial pattern and variations in the transverse dimensions of the dental arches.

\section{RESULTS}

The descriptive statistics of the variables revealed higher mean values at $\mathrm{T} 2$ than those found at $\mathrm{Tl}$. Thus, after an interval of five years all the variables analyzed showed some increase, and this difference was statistically significant at a level of $\mathrm{p} \leq 0.05$ for all variables studied (UICW, LICW, UIMW and LIMW) (Table 2).

The variable that showed the greatest variation was upper intercanine width, and the lowest variation was found between the lower molars (Fig 4). Descriptive statistics (Fig 5) and Spearman correlation test (Table 3) revealed that UIMW was the only variable that correlated with the facial pattern.

\section{DISCUSSION}

The longitudinal observation of how the set of features characterizing the dental arches evolves and interrelates is a reliable method to explain its normal development. The advantages are: the fact that variability between individuals is put into proper perspective; serial comparisons are enabled; temporary problems are suppressed over time; and any extraordinary events or errors in the measurements are more easily detected and corrected.

Despite substantial advantages, longitudinal studies are not so common due to certain hurdles that hinder or discourage researchers. ${ }^{21}$ Among the disadvantages are the longer time that is required to complete the studies, higher cost and reduced sample size over time. ${ }^{19,21}$ However, these limiting factors do not outweigh the excellent results obtained by the longitudinal studies.

In order to deal with some of the shortcomings of this longitudinal study, it is important above all to analyze results with caution.

TABLE 2 - Descriptive statistics of variables analyzed and Student's t-test for mean differences between the two observation times (T1 and T2).

\begin{tabular}{|c|c|c|c|c|c|c|}
\hline \multirow{2}{*}{ Variable } & \multirow{2}{*}{ Statistics } & \multicolumn{2}{|c|}{ Time } & \multirow{2}{*}{ Difference } & \multirow{2}{*}{$\mathrm{t}$} & \multirow[b]{2}{*}{$\mathbf{p}$} \\
\hline & & initial & final & & & \\
\hline \multirow{4}{*}{$\begin{array}{c}\text { Upper } \\
\text { Intercanine Width } \\
\text { (UICW) }\end{array}$} & mean & 30.94 & 34.15 & 3.283 & \multirow{4}{*}{-7.025} & \multirow{4}{*}{0.000} \\
\hline & standard deviation & 1.90 & 2.49 & - & & \\
\hline & minimum & 28.70 & 29.69 & - & & \\
\hline & maximum & 34.82 & 38.35 & - & & \\
\hline \multirow{4}{*}{$\begin{array}{l}\text { Lower } \\
\text { Intercanine Width } \\
\text { (LICW) }\end{array}$} & mean & 25.38 & 26.90 & 3.238 & \multirow{4}{*}{-3.967} & \multirow{4}{*}{0.001} \\
\hline & standard deviation & 2.17 & 1.61 & - & & \\
\hline & minimum & 21.15 & 23.71 & - & & \\
\hline & maximum & 28.13 & 29.28 & - & & \\
\hline \multirow{4}{*}{$\begin{array}{c}\text { Upper } \\
\text { Intermolar Width } \\
\text { (UIMW) }\end{array}$} & mean & 46.15 & 48.31 & 1.893 & \multirow{4}{*}{-6.149} & \multirow{4}{*}{0.000} \\
\hline & standard deviation & 2.78 & 2.47 & - & & \\
\hline & minimum & 41.64 & 44.84 & - & & \\
\hline & maximum & 50.48 & 52.04 & - & & \\
\hline \multirow{4}{*}{$\begin{array}{l}\text { Lower } \\
\text { Intermolar Width } \\
\text { (LIMW) }\end{array}$} & mean & 42.53 & 43.03 & 0.527 & \multirow{4}{*}{-2.154} & \multirow{4}{*}{0.046} \\
\hline & standard deviation & 2.23 & 2.79 & - & & \\
\hline & minimum & 39.95 & 38.23 & - & & \\
\hline & maximum & 45.83 & 46.53 & - & & \\
\hline
\end{tabular}




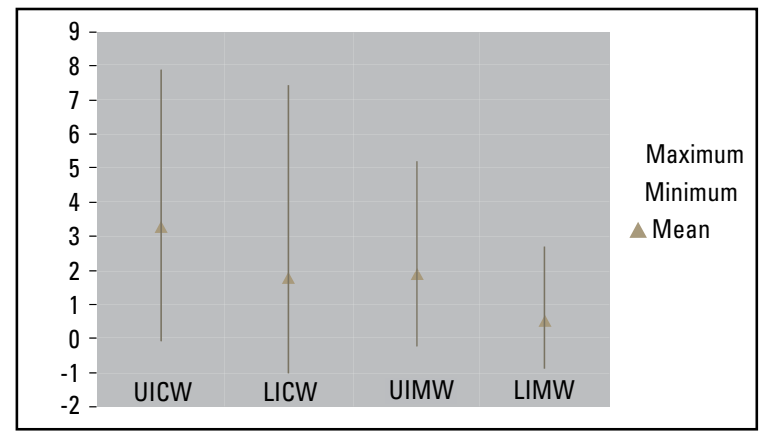

FIGURE 4 - Variation of the dimensions evaluated between $\mathrm{T} 1$ and T2 showing maximum and minimum variations found.

TABLE 3 - Spearman correlation test.

$\begin{array}{cccc}\text { Variable } & \begin{array}{c}\text { Spearman } \\ \text { Coefficient (R) }\end{array} & \mathbf{t} & \mathbf{p} \\ \text { UICW } & 0.05 & 0.19 & 0.850 \\ \text { LICW } & 0.31 & 13.23 & 0.203 \\ \text { UIMW } & 0.61 & 30.48 & \mathbf{0 . 0 0 8 ^ { * }} \\ \text { LIMW } & 0.29 & 12.06 & 0.245\end{array}$

${ }^{*} \mathrm{p}<0.001$

The number of subjects (n) diminished considerably in some groups, making the sample of brachyfacial patients become greatly reduced. Therefore interpretation of the results according to the facial pattern should be carefully used.

\section{Intercanine width}

Final values of upper and lower intercanine widths in relation to initial values showed statistically significant increases of $3.21 \mathrm{~mm}$ and 1.52 $\mathrm{mm}(\mathrm{p}=0.000$ and $\mathrm{p}=0.001)$, respectively, for the upper and lower arches. Several other studies that examined samples in a similar age range yielded results that are close to those observed in the present study. ${ }^{14,25}$ However, Sinclair and Little ${ }^{26}$ found a decrease of $0.75 \mathrm{~mm}$ when analyzing orthodontically untreated individuals aged from 7 to 17 years. This decrease can be explained by the age range differences between the samples, since, after the complete eruption of permanent teeth, a decrease in intercanine width occurs. ${ }^{2,25}$

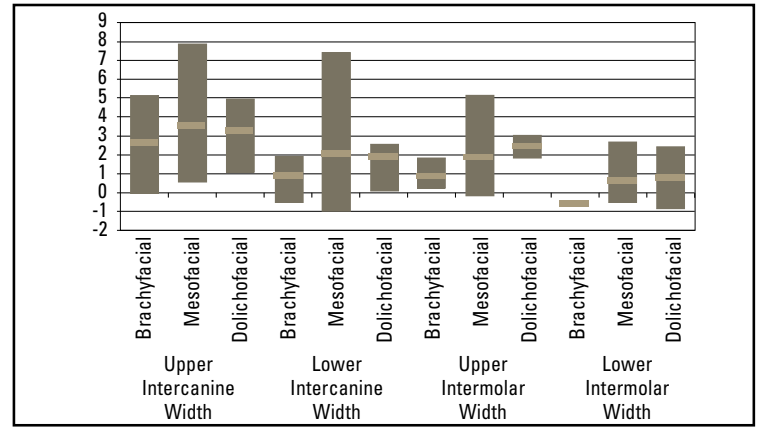

FIGURE 5 - Descriptive statistics of the changes observed between $\mathrm{T} 1$ and T2 for each facial pattern, showing means, maximum and minimum limits.

The clinical applicability of this outcome, considering the gradual increase in intercanine distances during the transition from deciduous to permanent dentition, can prove very helpful, confirming some treatment approaches which suggest the correction of crowding at a later stage. ${ }^{27}$

\section{Intermolar width}

The values found for upper and lower intermolar width in this study revealed a statistically significant increase from $\mathrm{T} 1$ to $\mathrm{T} 2 \mathrm{p}=0.000$ for UIMW and $\mathrm{p}=0.046$ for LIMW). Regarding the upper intermolar width the increase reached 2.16 $\mathrm{mm}$ and as to the mandibular intermolar width it increased $0.50 \mathrm{~mm}$. These values are similar to those observed in the literature. ${ }^{2,16,25}$ However, Moorrees $^{17}$ and Brown ${ }^{6}$ found stable intermolar widths in longitudinal studies involving subjects without prior orthodontic treatment.

\section{Relationship with the facial pattern}

In the present study, the analysis of variations in the intercanine and intermolar widths showed that only the upper intermolar width correlated significantly with the growth pattern $(p=0.008)$ as the value of the correlation coefficient $(R)$ was greater than 0.6 . The value of $\mathrm{R}^{2}(0.3721)$ shows that just over $37 \%$ of LIMW variations are explained by the facial pattern, while almost 63\% of the changes are determined by other variables which were not the focus of this study. 
In another study, which also did not take into account the gender and ethnicity of the evaluated patients, but only the relationship with the facial pattern, the lower intermolar widths were greater in individuals with a more horizontal pattern when compared to vertical ones. ${ }^{20}$

However, despite some studies concluding that there was no relationship between the transverse dimensions of the arches and the facial pattern ${ }^{9,12,20}$ there are others showing that it depends on the individual's gender, i.e., other determinant variables were identified. ${ }^{12}$

The literature shows that brachyfacial men tend to have larger maxillary and mandibular widths than mesofacial men. ${ }^{9}$ However, no significant differences were found when comparing the arch widths in brachyfacial versus mesofacial ${ }^{9}$ women.

In any case, studies that found relationships between facial pattern and transverse dimensions show increases in these dimension as the facial pattern becomes more horizontal. The findings were attributed to the muscle pattern of these patients. ${ }^{13,28}$

In the present study, although the Spearman's correlation test pointed to a relationship between facial pattern and variations in the transverse dimensions of the dental arches in only one of the variables studied (UIMW), decrease of the sample according to facial pattern may have generated a false negative.

However, it would be adequate to pursue longitudinal studies with a representative sample size of individuals during growth period, in a way that the subdivision into different facial patterns, as well as gender and race, could be made without drastically reducing the sample size. This type of study would also allow professionals above and beyond the mere identification of correlations between facial patterns and dental arch dimensions - to verify whether variations between dolichofacial, mesofacial and brachyfacial individuals become increasingly apparent as the individual grows or if such variations are already present at an early age.

\section{CONCLUSIONS}

Given the nature of this longitudinal study, the sample studied and the results achieved, the following conclusions could be drawn:

- There were increases in maxillary and mandibular intercanine widths.

- There were increases in maxillary and mandibular intermolar widths.

- A correlation was found between maxillary intermolar widths and facial pattern. 


\section{REFERENCES}

1. Arya BS, Savara BS, Thomas DR. Prediction of first molar occlusion. Am J Orthod. 1973;63(6):610-21.

2. Barrow SV, White JR. Developmental changes of the maxillary and mandibular dental arches. Angle Orthod. 1952;22(1):41-6.

3. Baume LJ. Physiological tooth migration and its significance for the development of occlusion I. The biogenetic course of the deciduous dentition. J Dent Res. 1950 Apr;29(2):123-32.

4. Bishara SE, Jakobsen JR, Treder J, Nowak A. Arch width changes from 06 weeks to 45 years of age. Am J Orthod Dentofacial Orthop. 1997:111(4):401-9.

5. Broadbent HA. New X-ray technique and its application to orthodontics. Angle Orthod. 1931;1(2):45-66.

6. Brown VP, Daugaard-Jensen I. Changes in the dentition from the early teens to the early twenties. Acta Odontol Scand. 1951;9(3-4):177-92

7. Carlsen DB, Meredith HV. Biologic variation in selected relationship of opposing posterior teeth. Angle Orthod. 1960;30(3):162-73.

8. Carter GA, McNamara JA. Longitudinal dental arch changes in adults. Am J Orthod Dentofacial Orthop. 1998;114(1):88-99.

9. Christie TE. Cephalometric patterns of adults with normal occlusion. Angle Orthod.1977;47(5):128-35.

10. Clinch L. Serial models of two cases of normal occlusion between birth and four years. Dent Rec. 1940;60(8):323-29.

11. Cunha JCM. Estudo morfológico dos arcos dentários decíduos com relação terminal em plano vertical e em degrau mesial [dissertação]. Piracicaba (SP): Universidade Estadual de Campinas; 1977.

12. Forster $\mathrm{CM}$, Sunga $\mathrm{E}$, Chung $\mathrm{CH}$. Relationship between dental arch width and vertical facial morphology in untreated adults. Eur J Orthod. 2008;30(3):288-94.

13. Kiliaridis S. Masticatory muscle influence on craniofacial growth. Acta Odont Scand. 1995;53(3):196-202.

14. Knott VB. Longitudinal study of dental arch width at four stages of dentition. Angle Orthod. 1972;42(4):387-95.

15. Lee RT. Arch width and form: a review. Am J Orthod Dentofacial Orthop. 1999;115(3):305-13.
16. Marshall S, Dawson D, Southard KA, Lee AN, Casko JS, Southard TE. Transverse molar movements during growth. Am J Orthod Dentofacial Orthop. 2003;124(6):615-24.

17. Moorrees CFA. The dentition of the growing child. Cambridge: Harvard University Press; 1959

18. Moorrees CFA, Gron AM, Lebret LM, Yen PK, Frohlich FJ. Growth studies of the dentition: a review. Am J Orthod. 1969;55(6):600-16

19. Moyers RE. Ortodontia. $4^{\text {th }}$ ed. Rio de Janeiro: Guanabara; 1991.

20. Nasby JA, Isaacson RJ, Worms FW, Speidel TM. Orthodontic extractions and facial skeletal pattern. Angle Orthod. 1972 42(2):116-22.

21. Valladares Neto J, Domingues MHMS, Capelozza Filho L. Pesquisa em Ortodontia: bases para a produção e a análise crítica. Rev Dental Press Ortod Ortop Facial. 2000;5(4):89-105.

22. Sanin C, Savara BS, Clarkson QC, Thomas DR. Prediction of occlusion by measurements of the deciduous dentition. Am J Orthod. 1970 Jun:57(6):561-72.

23. Sillman $\mathrm{JH}$. Changes in dental arches as a factor in orthodontics diagnosis. Am J Orthod. 1947;33(9):565.

24. Sillman JH. Clinical consideration of occlusion: A serial study. Am J Orthod. 1956;42(9):658-82.

25. Sillman JH. Dimensional changes of the dental arches: longitudinal study from birth to 25 years. Am J Orthod. 1964;50(11):824-42.

26. Sinclair PM, Little RM. Maturation of untreated normal occlusions. Am J Orthod. 1983;83(2):114-23.

27. Tausche E, Luck O, Harzer W. Prevalence of malocclusion in the early mixed dentition and orthodontic treatment need. Eur J Orthod. 2004;26(3):237-44.

28. Van Spronsen PH, Weijs WA, Prahl-Andersen B, Valk J, Van Finkel F. Relationships between jaw muscle cross-sections and normal craniofacial morphology, studied with magnetic resonance imaging. Eur J Orthod. 1991;13(5):351-61.

29. Zsigmondy O. Über die Veränderungen des Zahnbogens bei der zweiten Dentition. Arch F Anat. 1890. Helf 5.6, p. 367.

\section{Contact address}

Jucienne Salgado Ribeiro

Rua Emiliano Perneta, 680 - Conjunto 1205

Zip code: 80.420-080 - Curitiba/PR, Brazil

E-mail: jucienne@gmail.com 